\title{
Multivariate analysis of the factors involved in loss of renal differential function after laparoscopic partial nephrectomy: a role for warm ischemia time
}

\author{
Frédéric Pouliot, MD, PhD, FRCSC;, ${ }^{*+}$ Allan Pantuck, MD, MS, FACS, ${ }^{+}$Annie Imbeault, MD; ${ }^{*}$ Brian Shuch, MD; ${ }^{+}$ \\ Brian Calimlim, BSc; ${ }_{\text {; }}$ Jean-François Audet, MD, MSc, FRCSC;; David S. Finley, MD; ${ }_{\text {; }}^{*}$ Thierry Dujardin, MD*
}

See related article on page 96.

\begin{abstract}
Background: Partial nephrectomy (PN) is now the gold standard for the surgical treatment of small renal masses. We evaluated the effect of WIT and other factors on RDF assessed by preoperative and postoperative renal scintigraphy.

Methods: Between 2003 and 2008, 182 consecutive laparoscopic PN (LPN) were performed in an academic centre. Among those, 56 had mercaptoacetyl triglycine (MAG3) lasix renal scintigraphy preoperatively and postoperatively.

Results: Medians for age, preoperative estimated glomerular filtration rate and computed tomography scan tumour size were 62 years, $82 \mathrm{~mL} / \mathrm{min} / 1.73 \mathrm{~m}^{2}$ and $26 \mathrm{~mm}$, respectively. Median WIT and preoperative RDF were 30 minutes and $50 \%$, respectively. Median loss of RDF after surgery was $14 \%$. Linear regression curves showed that loss in RDF rate was $0.2 \%$ per minute when WIT was $<30$ minutes and $0.7 \%$ per minute when WIT was $\geq 30$ minutes. In multivariate analysis, length of WIT and endophytic tumour location were associated with a statistically significant loss of RDF $(p<0.05)$, but only in the group who experienced $>30$ minutes of WIT.

Interpretation: Our results suggest that the factors associated with loss of RDF are not the same before and after 30 minutes of WIT and that the rate of loss in RDF increases after 30 minutes. Since, the effect of WIT is small up to 30 minutes, we believe that surgery should focus on limiting the resection of normal parenchyma and to ensure negative margins and hemostasis, rather than on premature unclamping.
\end{abstract}

Cite as: Can Urol Assoc J 2011;5(2):89-95; D01:10.5489/cuaj.10044

\section{Résumé}

Contexte : La néphrectomie partielle (NP) est maintenant la norme thérapeutique pour le traitement chirurgical des petites masses rénales. Nous avons évalué l'effet du temps d'ischémie chaude et d'autres facteurs sur la fonction rénale différentielle par scintigraphie rénale préopératoire et postopératoire.

Méthodologie : Entre 2003 et 2008, 182 NP par laparoscopie ont été effectuées de façon consécutive dans un centre universitaire. De ces cas, 56 ont subi une scintigraphie rénale Lasix au MAG3 (mercaptoacétyltriglycine) avant et après l'opération.

Résultats : Les valeurs médianes pour l'âge, le taux de filtration glomérulaire préopératoire évalué et la taille de la tumeur mesurée par tomodensitométrie étaient de 62 ans, $82 \mathrm{~mL} / \mathrm{min} / 1,73 \mathrm{~m}^{2}$ et $26 \mathrm{~mm}$, respectivement. Le temps médian d'ischémie chaude et la fonction rénale différentielle avant l'opération étaient de 30 minutes et de $50 \%$, respectivement. La perte médiane de fonction rénale différentielle après l'intervention était de $14 \%$. Les courbes de régression linéaire ont révélé que la perte de fonction rénale différentielle était de 0,2\% par minute lorsque le temps d'ischémie chaude était inférieur à 30 minutes et de 0,7\% par minute lorsque le temps d'ischémie chaude était $\geq 30$ minutes. Dans I'analyse multivariée, la durée de l'ischémie chaude et une tumeur endophytique ont été associées à une perte de fonction rénale différentielle significative sur le plan statistique $(p<0,05)$, mais seulement dans le groupe ayant subi une ischémie chaude de plus de 30 minutes. Interprétation : Nos résultats portent à croire que les facteurs associés à la perte de fonction rénale différentielle diffèrent avant et après 30 minutes d'ischémie chaude, et que le taux de perte de fonction rénale différentielle augmente après 30 minutes. Comme l'effet de l'ischémie chaude est minimal lorsque celle-ci est de 30 minutes ou moins, nous croyons qu'il faut chercher à limiter la résection du parenchyme normal et assurer des marges négatives et l'hémostase plutôt que de viser un déclampage prématuré.

\section{Introduction}

The annual number of patients with renal cell carcinoma (RCC) has increased in the last decade secondary in part due to an increase in incidentally found tumours; ${ }^{1}$ the highest increase has been observed in the incidence of localized tumours. ${ }^{2,3}$ This trend has led to the more frequent use of partial nephrectomy (PN), which has now become a standard, if not the preferred treatment, for smaller renal masses. ${ }^{4}$ One of the modifiable factors associated with the loss of renal function (RF) during PN is warm ischemia time (WIT), but the safe duration of clamping time is unkown. Some studies based on creatinine or estimated glomerular filtration rate (eGFR) suggest that WIT should be kept under 20 minutes, while others have suggested 40 minutes as a cut-off. ${ }^{5-11}$ This discrepancy between studies underscores the 
Pouliot et al.

need for homogenous data using RF tools that evaluate the damage to the operated kidney.

To evaluate the impact of WIT after laparoscopic PN (LPN), we analyzed its effect on the loss of renal differential function (RDF) on the operated kidney in a series of LPN. In a small cohort of patients, we demonstrate that the factors associated with loss in RDF before and after 30 minutes are different.

\section{Methods}

\section{Data collection and patient selection}

We included 56 patients who had a MAG3-lasix renal scintigraphy performed both preoperatively and postoperatively from a cohort of 182 patients who underwent LPN for organ-confined enhancing tumours on preoperative imaging. All procedures were performed by 1 surgeon in a single institution. Tumour size was defined by the longest single dimension of the lesion on the computed tomography scan. The localization of the tumour was defined as endophytic if more than $5 \mathrm{~mm}$ of the tumour was located in the renal parenchyma consistent with the Johntson classification. ${ }^{12}$

\section{Transperitoneal laparoscopic partial nephrectomy technique}

A 4-port approach was used. Initial dissection was directed toward defining the renal hilum. The renal hilum was crossclamped with a Aesculap (Aesculap, Inc., Center Valley, PA) noncrushing laparoscopic bulldog clamp or with an Aesculap Satinsky clamp. The lesion with a rim of normal parenchyma was sharply resected. Renal repair began with runs of sutures to close the collecting system. Subsequently, 2 or 3 parenchymal buttress sutures were placed. FloSeal (Baxter Healthcare Corporation, Hayward, CA) and polyglactin mesh rolls (Surgicel, Ethicon 360, Inc.) were placed to fill the parenchymal void and stabilized by tying down the buttress sutures. A Jackson-Pratt drain was placed.

\section{Follow-up}

Serum creatinine $(\mathrm{Cr})$ was measured preoperatively and postoperatively at day 1 , at 3 months and at the last date of follow-up. Renal function was evaluated by assessing the split RF using MAG-3-lasix scintigraphy at a median of 10 days.

\section{Statistical analysis}

Discrete variables were reported as a percentage and continuous variables as a median and mean \pm standard deviation. Differences between patient groups among the discrete variables were tested using the chi-square test, while differences among continuous variables were tested using the two-sample t-test or the one-way ANOVA. The association of RDF with each characteristic was investigated using a univariate linear regression model. When investigating the relationship of RDF across different WIT intervals, the oneway ANOVA model was used and a linear contrast was used to test for a linear trend. When investigating the relationship between RDF and WIT (measured continuously), a four-degree polynomial curve was fitted. Derivatives of the curve's equation were calculated to obtain the WIT where the maximal change in the RDF loss rate occurred. To adjust for possible confounders, multivariate linear regression models were also used. All analyses were conducted using SAS version 9.1.3 (SAS Institute Inc., Cary, NC).

\section{Results}

We detailed the characteristics of the patients (Table 1). No statistical difference was observed between the 56 patients selected for the study and the other 130 patients of our series, with the exception of tumour stage, WIT, postoperative creatinine and eGFR. Of note, the WIT in our cohort of 56 patients was on average $29.8 \pm 8.8$ minutes (range 9-60 minutes) and loss of RDF was on average $14.2 \pm$ $9.7 \%$. Endophytic location of the tumour, WIT, postoperative eGFR, operative time and blood loss were associated with a loss of RDF (Table 2). Since WIT was the modifiable factor with the strongest association, we first analyzed the effect of WIT at different intervals on loss of RDF. As the WIT increases, there is a statistically significant increase in loss of RDF in univariate analysis (Table 3). Next, we evaluated whether the loss of WIT was the same over time by plotting the effect of WIT as a continuous variable on the RDF of the operated kidney (Fig. 1). A polynomial curve drawn from the relation between WIT and loss in RDF illustrates that the rate of loss of RDF (\% per minute) before and after 30 minutes is not the same. Almost two separate linear curves are observed before and after 30 minutes. The calculated point of inflection (point of maximal change in the rate of loss in RDF) of this polynomial curve is 32 minutes. We next analyzed the relation between WIT and loss in RDF using linear regression analysis before and after 30 minutes (data not shown). The coefficient of determination $\left(\mathrm{r}^{2}\right)$ of the two linear regression curves was not the same $\left(r^{2}=0.06\right.$ before vs. $r^{2}=0.39$ after 30 minutes). Therefore, the discrepancy between the two coefficients of correlation suggests that there is a different association between WIT and loss in RDF for the two groups. Hence, we constructed two multivariate linear regression models: one with the group WIT $<30$ minutes and another with the group WIT $\geq 30$ minutes. The characteristics of our two groups were similar except for loss in RDF, hypertension (HTN) and WIT (Table 4). 
Table 1. Characteristics of patients in our series of laparoscopic partial nephrectomy with or without renal scintigraphy

\begin{tabular}{|c|c|c|c|c|c|}
\hline \multirow{3}{*}{ Characteristics } & \multicolumn{4}{|c|}{ Renal scintigraphy } & \multirow[b]{3}{*}{$p$ value } \\
\hline & \multicolumn{2}{|c|}{ Yes $(n=56)$} & \multicolumn{2}{|c|}{ No $(n=130)$} & \\
\hline & Value & Median & Value & Median & \\
\hline \multicolumn{6}{|l|}{ Patient } \\
\hline Age (years) & $62 \pm 11$ & 62 & $58 \pm 12$ & 59 & 0.06 \\
\hline Female (\%) & 46 & - & 47 & - & 0.92 \\
\hline BMI $\left(\mathrm{kg} / \mathrm{m}^{2}\right)$ & $28 \pm 5$ & 27 & $29 \pm 6$ & 28 & 0.30 \\
\hline Diabetes (\%) & 17 & - & 17 & - & 0.90 \\
\hline HTN (\%) & 30 & - & 26.4 & - & 0.80 \\
\hline ASA (\%) & & & & & 0.11 \\
\hline 1 & 43 & - & 41 & & \\
\hline 2 & 35 & - & 45 & & \\
\hline 3 & 22 & - & 14 & & \\
\hline \multicolumn{6}{|l|}{ Renal function } \\
\hline Preoperative eGFR (MDRD) & $78 \pm 19$ & 82 & $82 \pm 19$ & 81 & 0.16 \\
\hline Preoperative creatinine $(\mu \mathrm{M})$ & $87 \pm 29$ & 83 & $82 \pm 20$ & 81 & 0.23 \\
\hline Preoperative RDF (\%) & $50 \pm 8$ & 50 & nd & nd & nd \\
\hline Postoperative RDF (\%) & $36 \pm 12$ & 36 & nd & nd & nd \\
\hline Postoperative eGFR (MDRD) & $63 \pm 16$ & 63 & $72 \pm 18$ & 70 & 0.005 \\
\hline Postoperative creatinine $(\mu \mathrm{M})$ & $105 \pm 36$ & 100 & $94 \pm 29$ & 89 & 0.02 \\
\hline 3 months eGFR (MDRD) & $68 \pm 16$ & 67 & $74 \pm 19$ & 73 & 0.08 \\
\hline \multicolumn{6}{|l|}{ Tumour } \\
\hline Right side (\%) & 57 & - & 49 & - & 0.35 \\
\hline CT-size $(\mathrm{cm})$ & $3.2 \pm 1.6$ & 2.6 & $3.2 \pm 1.4$ & 3.0 & 0.92 \\
\hline Exophytic tumour (\%) & 27 & - & 18 & - & 0.25 \\
\hline Pathological stage (\%) & - & - & - & - & 0.008 \\
\hline pT1a & 62 & - & 78 & - & - \\
\hline pT1b & 8 & & 14 & & \\
\hline pT2 & 8 & & 2 & & \\
\hline рT3 & 23 & & 7 & & \\
\hline Furhman grade (\%) & & & & & 0.32 \\
\hline Grade $1-2$ & 83 & & 73 & & \\
\hline Grade 3-4 & 17 & & 28 & & \\
\hline \multicolumn{6}{|l|}{ Operative } \\
\hline WIT (minutes) & $30 \pm 9$ & 30 & $26 \pm 9$ & 24 & 0.006 \\
\hline OR-time (minutes) & $123 \pm 29$ & 120 & $124 \pm 27$ & 120 & 0.95 \\
\hline Blood loss (mL) & $181 \pm 259$ & 50 & $176 \pm 258$ & 100 & 0.85 \\
\hline \multicolumn{6}{|l|}{ Postoperative } \\
\hline Hospitalization (days) & $4.6 \pm 3.3$ & 4 & $4.0 \pm 2.2$ & 4 & 0.18 \\
\hline Complications (\%) & 25 & - & 28 & - & 0.42 \\
\hline
\end{tabular}

BMI: body mass index; HTN: hypertension; ASA: American Society of Anesthesiologists (ASA) score; eGFR: estimated glomerular filtration rate; MDRD: modification of diet in renal disease;

RDF: renal differential function; $\mathrm{CT}$ : computed tomography; WIT: warm ischemia time; OR: operating room; nd: not determined.

When the data were analyzed using the multivariate regression models, the factors with the strongest association with a loss in RDF (but not statistically significant) for the group WIT $<30$ were HTN $(p=0.09)$, solid texture $(p=0.06)$ and endophytic location of the tumour ( $p=0.08$ ) (Table $5)$. The WIT was not associated with loss in RDF. In the group WIT $\geq 30$, WIT was the main factor associated with a loss in RDF ( $p=0.002)$, while the endophytic location of the tumour was the other statistically significant factor $(p=0.02)$. We next determined the rate of loss of RDF when only considering WIT as a factor. We used our models to correct the loss in RDF for every factor other than WIT. By comparing the linear relation between WIT and loss of RDF between the two groups, we observed that the adjusted rate of RDF-loss was 3.5-fold higher in the group with WIT $\geq 30$ minutes than the group $<30$ minutes. The calculated rate of loss in RDF was $0.2 \%$ per minute in the group WIT $<30$ as compared to $0.7 \%$ per minute in the WIT $\geq 30$ group (Fig. 2 ). 
Pouliot et al.

\begin{tabular}{lc}
\hline \multicolumn{2}{l}{ Table 2. Factors associated with loss in renal differential } \\
function in univariate analysis \\
\hline Characteristics & p value \\
\hline Patient related & \\
Age & 0.98 \\
Male sex & 0.44 \\
BMI & 0.68 \\
HTN & 0.80 \\
Diabetes & 0.15 \\
\hline Renal function related & \\
Preoperative RDF & 0.36 \\
Creatinine & 0.64 \\
eGFR Preoperative (MDRD) & 0.39 \\
eGFR Postoperative (MDRD) & 0.003 \\
Postoperative creatinine ( $\mu$ M) & 0.68 \\
Creatinine at 3 months (MDRD) & 0.28 \\
\hline Tumour related & \\
Right side & 0.71 \\
CT size & 0.16 \\
Exophytic location & 0.003 \\
Pathological stage & 0.72 \\
Histological type & 0.26 \\
Furhman grade & 0.66 \\
\hline Surgery related & \\
OR time & 0.03 \\
Blood loss & 0.03 \\
Margin & 0.07 \\
WIT (minutes) & $<0.001$ \\
Urinary leak & 0.95 \\
Transfusion & 0.63 \\
Ureteral catheter usage & 0.15 \\
Complications (all) & 0.47 \\
Complications (urological) & 0.47 \\
\hline BMI: body mass index; HTN: hypertension; eGFR: estimated glomerular filtration rate; \\
MDRD: modification of diet in renal disease; RDF: renal differential function; CT: computed \\
tomography; WIT: warm ischemia time; OR: operating room. \\
\hline
\end{tabular}

\section{Discussion}

In this study, we have used preoperative and postoperative MAG-3-lasix renal scintigraphy to evaluate the factors most responsible for a loss of RDF after laparoscopic partial nephrectomy. We have identified WIT as the factor with the strongest association with a loss of RDF in multivariate analysis. We also demonstrated that the effect of WIT varies over time, being 3.5-fold higher after 30 minutes than before.

Accumulating evidence from population-based analyses demonstrates that impaired renal function has adverse effects on several health outcomes. ${ }^{13}$ Moreover, it has been shown that $24 \%$ of patients with cT1 a tumours have an eGFR of less than $60 \mathrm{~mL} / \mathrm{min} / 1.73 \mathrm{~m}^{2} .{ }^{14}$ The evidence heightens the interest in techniques that have the potential to preserve RF. Indeed, the identification of modifiable factors that could alter renal function during or after nephron-sparing nephrec-

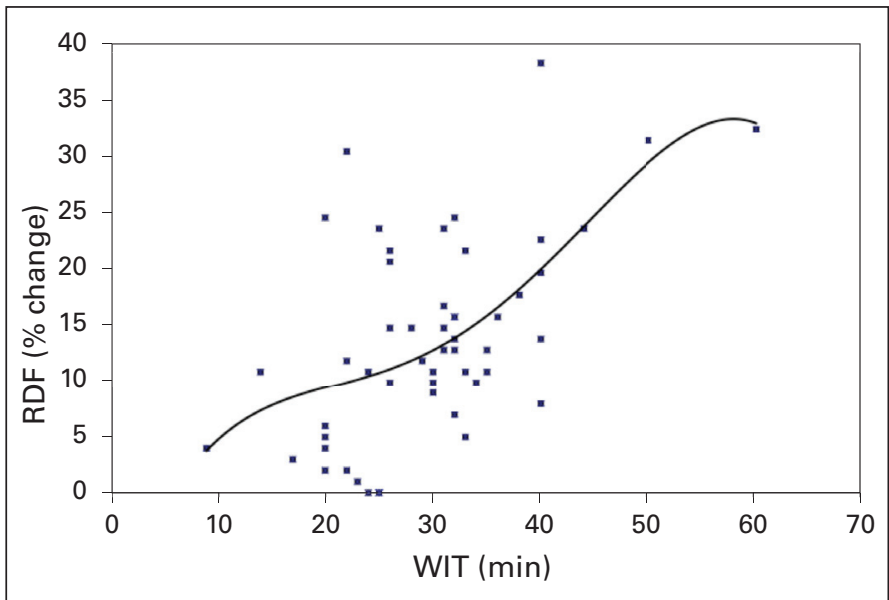

Fig. 1. Effect of WIT on RDF. Patients undergoing LPN had a preoperative and a postoperative renal scintigraphy and the change in RDF was plotted against WIT. The rate of change in loss in RDF increases after 30 minutes. The point of maximal inflection of the curve was calculated at 32 minutes.

tomy is of the utmost importance to minimize the effect of the intervention on the operating kidney. Most studies have based their conclusions on serum creatinine and eGFR, two parameters that do not accurately reflect the damage to the operating kidney. ${ }^{15}$ For instance, Porpiglia and colleagues have reported that WIT was associated with loss in RDF, while it did not affect the eGFR, showing the higher sensitivity of RDF to detect renal damage. Since the goal of PN is to preserve RF on the operating kidney, we believe that looking at loss of RDF or eGFR by renal scintigraphy is the best method to identify damage to the operating kidney. On the other hand, RF assessment using eGFR would be better to delineate the patients that are at risk for global RF deterioration and subsequent renal insufficiency. In multivariate analysis, only the endophytic location of the tumour and WIT were statistically associated with loss of RDF. We believe that the association of tumour location and loss of RDF occurs due to extirpation of normal parenchyma when there is more than more than $5 \mathrm{~mm}$ of parenchymal incursion (our definition of endophytic). Interestingly, the association between loss of RDF and the size of normal parenchymal margins resected almost achieved statistical significance $(p=0.07)$. A study with more power would likely achieve significance. Three other studies have used renal scintigraphy to evaluate factors that can predict loss of RF on the operating kidney (Appendix 1). The removal of normal parenchyma seems to be a common factor associated with loss in RF. ${ }^{15,16}$ We also showed that WIT is strongly associated with loss in RDF. On average, the absolute loss in RDF was $14 \%$ and relative loss in RDF was $29 \%$ (relative loss = absolute loss RDF/preoperative RDF $\times 100$ ). This finding concurs with three recent studies that showed that loss in RF by renal scintigraphy was of $29 \%,{ }^{16} 29 \%{ }^{17}$ and $24 \%{ }^{15}$ in the early postoperative period when using renal scintigraphy 
Laparoscopic partial nephrectomy and WIT

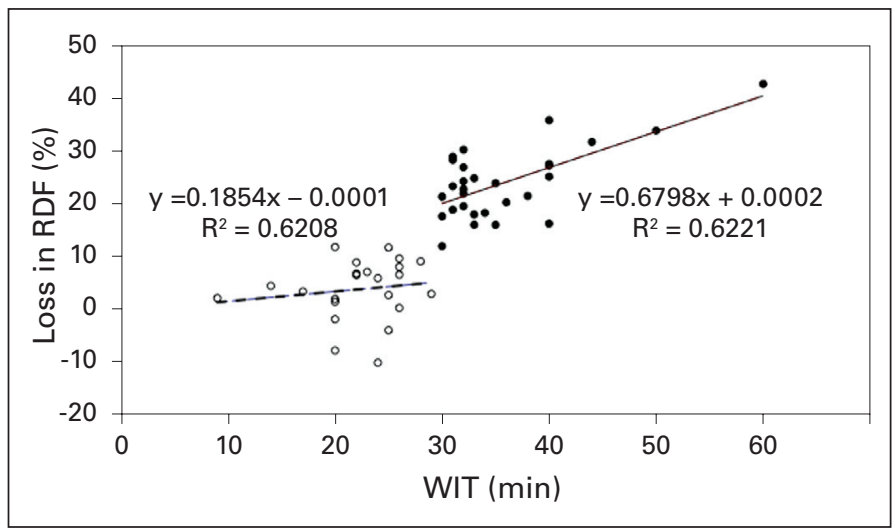

Fig. 2. Effect of WIT on the loss of RDF after adjusting for confounding factors using multivariate analysis regression models.

(Appendix 1). Based on these series and the current study, the estimated loss of RDF on the operating kidney after a LPN with a WIT of 30 minutes for a tumour of about $3 \mathrm{~cm}$ should be expected to be between $25 \%$ and $30 \%$.

The difference in the factors responsible for a loss of RDF before and after 30 minutes is interesting from a clinical perspective. We have shown in a multivariate regression model that the factors associated with loss of RDF before 30 minutes are patient- or tumour -related, while those associated loss of RDF after 30 minutes are tumour- and surgery-related. An important finding of this study is that the impact of WIT before 30 minutes is minimal, whereas after 30 minutes, it is the main factor associated with a loss of RDF. Since our series is not sufficiently powered to conclude that WIT has no impact on RDF before 30 minutes, it does show that its effect is minimal when loss of RDF is corrected for other patient- and tumour-related factors. Therefore, we believe that surgeons should focus on minimizing the removal of normal parenchyma, ensur-

\begin{tabular}{|c|c|c|c|}
\hline \multirow{2}{*}{ WIT (min) } & \multirow{2}{*}{$\mathbf{n}$} & \multicolumn{2}{|c|}{ RDF loss* \pm} \\
\hline & & Average & SD \\
\hline$<20$ & 8 & 7.5 & 7.6 \\
\hline $20-30$ & 20 & 11.8 & 9.2 \\
\hline $30-40$ & 24 & 17.0 & 8.4 \\
\hline$>40$ & 3 & 29.7 & 4.9 \\
\hline
\end{tabular}

ing negative margins and careful hemostasis as opposed to an unnecessary premature unclampling of the renal artery before 30 minutes. By analyzing loss in RDF as a continuous variable, we also demonstrated that there is no specific time at which the renal artery clamp should be removed, but instead that the rate of loss of RDF changes around 30 minutes. We have estimated that the rate of loss in RDF due to WIT increases to $0.7 \%$ per minute after 30 minutes. For a kidney with a 50\% RDF, this translates into a loss of $1.4 \%$ per minute of functional parenchyma. This estimated rate may help surgeons plan their surgeries based on the preoperative RF of the patient, the characteristics of the tumour and the estimated clamping time. Many techniques have been described to limit ischemic damages during LPN. such as renal cooling, early unclamping, on-demand clamping and parenchymal compression with a Kaufman clamp, all of which should be considered if the WIT is anticipated to be longer than 30 minutes. ${ }^{18}$ Open PN should also be strongly considered with or without ice cooling in cases where LPN is anticipated to be difficult.

Our study has the limitation of using an early postoperative renal scintigraphy and therefore, the ischemic damage observed may be more reflective of acute renal ischemic

Table 4. Comparative analysis of characteristics of the patients with warm ischemia times $<$ or $\geq$ than 30 minutes that were used for the multivariate analysis

\begin{tabular}{|c|c|c|c|c|c|}
\hline \multirow{3}{*}{ Variable } & \multicolumn{4}{|c|}{ Descriptive statistics } & \multirow{3}{*}{$p$ value } \\
\hline & \multicolumn{2}{|c|}{ WIT $<30$ minutes $(n=23)$} & \multicolumn{2}{|c|}{ WIT $\geq 30$ minutes $(n=29)$} & \\
\hline & Mean & SD & Mean & SD & \\
\hline Change in RDF & 10.6 & 9.4 & 17.6 & 8.9 & 0.01 \\
\hline \multicolumn{6}{|l|}{ Patient related } \\
\hline HTN (\%) & 46 & - & 17 & - & 0.04 \\
\hline Diabetes (\%) & 13 & - & 21 & - & 0.49 \\
\hline Preoperative RDF (\%) & 49 & - & 50.5 & 9.0 & 0.42 \\
\hline \multicolumn{6}{|l|}{ Tumour related } \\
\hline Endophytic (\%) & 64 & - & 80 & - & 0.23 \\
\hline Solid texture (\%) & 80 & - & 73 & - & 0.75 \\
\hline Pathological stage T1 (\%) & 80 & - & 73 & - & 0.75 \\
\hline \multicolumn{6}{|l|}{ Surgery related } \\
\hline WIT (min) & 22.5 & 4.5 & 35.8 & 6.6 & $<0.001$ \\
\hline Blood loss (g/L) & 20.6 & 11.0 & 24.6 & 15.8 & 0.30 \\
\hline
\end{tabular}


Pouliot et al.

\begin{tabular}{|c|c|c|c|c|c|c|}
\hline \multirow{3}{*}{ Variable } & \multicolumn{6}{|c|}{ Multivariate analysis } \\
\hline & \multicolumn{3}{|c|}{ WIT $<30$ minutes $(n=23)$} & \multicolumn{3}{|c|}{ WIT $\geq 30$ minutes $(n=29)$} \\
\hline & Estimate & SE & $p$ value & Estimate & SE & $p$ value \\
\hline \multicolumn{7}{|l|}{ Patient related } \\
\hline HTN (\%) & -6.6 & 3.6 & 0.09 & 2.9 & 3.3 & 0.4 \\
\hline Diabetes (\%) & 4.6 & 6.1 & 0.46 & -3.6 & 2.9 & 0.22 \\
\hline Preoperative RDF (\%) & 0.1 & 0.3 & 0.68 & -0.2 & 0.2 & 0.28 \\
\hline \multicolumn{7}{|l|}{ Tumour related } \\
\hline Endophytic (\%) & 6.8 & 3.5 & 0.08 & 8.9 & 3.6 & 0.02 \\
\hline Solid texture (\%) & 10.1 & 4.9 & 0.06 & -5.1 & 3.2 & 0.12 \\
\hline $\begin{array}{l}\text { Pathological stage } \\
\text { T1 (\%) }\end{array}$ & 6.3 & 5.3 & 0.25 & -1.9 & 2.8 & 0.5 \\
\hline \multicolumn{7}{|l|}{ Surgery related } \\
\hline WIT (min) & 0.2 & 0.4 & 0.64 & 0.7 & 0.2 & 0.002 \\
\hline Blood loss (g/L) & 0.2 & 0.2 & 0.21 & 0.1 & 0.1 & 0.46 \\
\hline
\end{tabular}

WIT: warm ischemia time; RDF: renal differential function; HTN: hypertension; SE: standard error; confidence interval $=95 \%$.

injuries than the chronic damage responsible for late renal insufficiency. However, since loss of RDF is greater immediately after surgery, this period probably allows for a more sensitive assessment of factors involved. Hence, we have shown that WIT has little impact on renal function before 30 minutes in the early postoperative period (the period of maximal acute injury), which might reinforce our conlusion that surgery should focus on surgical precision rather than WIT before 30 minutes.

Another limitation of our study is the use of RDF as the measure of renal function. Because it is relative to the function of the other kidney, this measure cannot be extended to every patient, especially those with an asymmetric renal function, solitary kidney or comorbidities which affect renal function. Finally, the small number of patients included in the series might have limited our ability to detect significant factors involved in loss of RDF despite our efforts to perform a multivariate statistical analysis. Further studies with more patients will be needed to confirm our results.

\section{Conclusion}

Our multivariate analysis suggests that the effect of WIT on RDF of the operated kidney is not the same before and after 30 minutes. Since WIT has less impact on loss of RDF before 30 minutes, this suggests that LPN surgery should focus on limiting the resection margins, careful closure of the collecting system and hemostasis. After 30 minutes of WIT, the rate of loss of RDF increases and minimizing the loss of RDF should be the priority.

*Centre Hospitalier Universitaire de Québec, Université Laval, Québec, QC; †'Institute of Urologic Oncology, David Geffen School of Medicine, University of California at Los Angeles, Los Angeles, CA
Dr. Pouliot was supported in part by a scholarship from Les Bourses McLaughlin du Doyen, a scholarship from the Association des Urologues du Québec and a scholarship from the CMDP (Committee of physicians, dentists and pharmacists) of the Laval University Hospital Centre.

Competing interests: None declared.

This paper has been peer-reviewed.

\section{References}

1. Pantuck AJ, Zisman A, Belldegrun AS. The changing natural history of renal cell carcinoma. I Urol 2001;166:1611-23.

2. Chow WH, Devesa SS, Warren JL, et al. Rising incidence of renal cell cancer in the United States. JAMA 1999;281:1628-31.

3. Hock LM, Lynch J, Balaii KC. Increasing incidence of all stages of kidney cancer in the last 2 decades in the United States: an analysis of surveillance, epidemiology and end results program data. J Urol 2002; $167: 57-60$

4. Liungberg B, Hanbury DC, Kuczyk MA, et al. Renal cell carcinoma guideline. Eur Urol 2007;51:1502-10

5. Thompson RH, Frank I, Lohse CM, et al. The impact of ischemia time during open nephron sparing surgery on solitary kidneys: a multi-institutional study. J Urol 2007;177:471-6.

6. Abouassaly R, Lane BR, Novick AC. Active surveillance of renal masses in elderly patients. I Urol 2008; 180:505-8; discussion 508-9.

7. Colombo JR Jr, Haber GP, Jelousek JE, et al. Seven years after laparoscopic radical nephrectomy: oncologic and renal functional outcomes. Urology 2008;71:1149-54.

8. Foyil $K V$, Ames $C D$, Ferguson $G G$, et al. Longterm changes in creatinine clearance after laparoscopic renal surgery. J Am Coll Surg 2008;206:511-5.

9. Godoy G, Ramanathan V, Kanofsky JA, et al. Effect of warm ischemia time during laparoscopic partial nephrectomy on early postoperative glomerular filtration rate. J Urol 2009;181:2438-43; discussion 2443-5.

10. Becker F, Van Poppel H, Hakenberg OW, et al. Assessing the Impact of Ischaemia Time During Partial Nephrectomy. Eur Urol 2009;56:625-35.

11. Desai MM, Gill IS, Ramani AP, et al. The impact of warm ischaemia on renal function after laparoscopic partial nephrectomy. BJU Int 2005;95:377-83.

12. Johnston WK 3rd, Montgomery JS, Seifman BD, et al. Fibrin glue v sutured bolster: lessons learned during 100 laparoscopic partial nephrectomies. J Urol 2005;174:47-52. 


\begin{tabular}{|c|c|c|c|c|c|}
\hline \multirow{2}{*}{ Author } & \multirow{2}{*}{$\mathbf{n}$} & \multirow{2}{*}{ Tumour size $(\mathbf{c m})$} & \multirow{2}{*}{ WIT } & \multicolumn{2}{|c|}{ Loss in RF (\%) } \\
\hline & & & & Average (\%) & Associated factors \\
\hline Porpiglia et al ${ }^{12}$ & 18 & 3.4 & 39 & 24 & $\begin{array}{l}\text { WIT, size of normal } \\
\text { parenchyma removed }\end{array}$ \\
\hline Song et $\mathrm{al}^{13}$ & 117 & 2.9 & 28 & 29 & $\begin{array}{l}\text { Age, kidney volume loss, } \\
\text { upper pole location }\end{array}$ \\
\hline Funahashi et $\mathrm{al}^{14}$ & 30 & 3.2 & 24 & 29 & WIT \\
\hline Present study & 56 & 3.2 & 29 & $28^{a}$ & $\begin{array}{c}\text { WIT, endophytic location of } \\
\text { the tumour }\end{array}$ \\
\hline
\end{tabular}

13. Go AS, Chertow GM, Fan D, et al. Chronic kidney disease and the risks of death, cardiovascular events, and hospitalization. N Engl J Med 2004;351:1296-305.

14. Huang WC, Levey AS, Serio AM, et al. Chronic kidney disease after nephrectomy in patients with renal cortical tumours: a retrospective cohort study. Lancet Oncol 2006;7:735-40.

15. Porpiglia F, Renard J, Billia $M$, et al. Is renal warm ischemia over 30 minutes during laparoscopic partial nephrectomy possible? One-year results of a prospective study. Eur Urol 2007;52:1170-8.

16. Song C, Bang JK, Park HK, et al. Factors influencing renal function reduction affer partial nephrectomy. J Urol 2009; 181:48-53; discussion 54.

17. Funahashi $Y$, Hattori R, Yamamoto $T$, et al. Ischemic renal damage after nephron-sparing surgery in patients with normal contralateral kidney. Eur Urol 2009;55:209-15. Epub 2008 Aug 5.
18. Berger $A$, Crouzet $S$, Canes $D$, et al. Minimally invasive nephron-sparing surgery. Curr Opin Urol 2008; 18:462-6.

Correspondence: Dr. Thierry Dujardin, Assistant Professor, Laval University, Centre Hospitalier Universitaire de Québec, Pavillon Hôtel-Dieu de Québec, 11 Côte du Palais, Québec, QC GIR 2J6; fax: 418-691-5020; th.dujardin@videotron.ca 


\title{
COMMENTARY
}

\section{Determining optimal surgical care for patients with renal masses}

\author{
Robert Abouassaly, MD, MSc, FRCSC
}

See related article on page 89 .

Cite as: Can Urol Assoc J 2011;5(2):96; D01:10.5489/cuaj.11046

$\mathrm{T}$ he recent literature has emphasized the importance of renal function on life expectancy and cardiovascular morbidity. This has been demonstrated in both the medical ${ }^{1}$ and surgical literature, ${ }^{2,3}$ and has led to the expansion of the indications for partial nephrectomy in treatment of renal masses. In fact, the American Urological Association guidelines for the management of clinical stage 1 renal masses recommend partial nephrectomy be considered the standard of care in tumours $<4 \mathrm{~cm}$ when judged to be technically feasible by a urologic surgeon. ${ }^{4}$

The current article evaluates the effect of warm ischemia time and other clinical variables on renal differential function measured by MAG3-lasix renal scintigraphy. ${ }^{5}$ They conclude that factors associated postoperative renal function were not the same before and after 30 minutes, and that the rate of functional loss increases significantly after 30 minutes. However, drawing any firm conclusions or altering clinical practice based on these findings may not be advisable. Firstly, this study assessed renal function as a median of 10 days after surgery, which is more reflective of acute kidney injury rather than long-term renal function. And it is likely that long-term renal function is of greater clinical importance. Secondly, this article is severely limited by its small sample size. Performing multivariable analyses with such small numbers risks overfitting the model, and is statistically inadvisable. Nonetheless, this article confirms the findings of others that renal functional loss is not linearly associated with warm ischemia at the time of partial nephrectomy, and that functional deterioration appears to accelerate with time. ${ }^{6}$ However, studies continue to find that any period of ischemia results in a negative effect on ultimate renal function. ${ }^{7}$
In summary, although level-1 evidence is lacking, observational studies suggest the importance of renal functional preservation in the treatment of small renal masses, which is best achieved with partial nephrectomy and minimization of renal ischemia when extirpation is deemed necessary. However, prospective, preferably randomized, studies are needed to more convincingly determine optimal surgical care in patients with renal masses.

Urological Institute, University Hospitals Case Medical Center, Cleveland, $\mathrm{OH}$

Competing interests: None declared.

This paper has been peer-reviewed.

\section{References}

1. Go AS, Chertow GM, Fan D, et al. Chronic kidney disease and the risks of death, cardiovascular events, and hospitalization. N Engl J Med 2004;351:1296-305.

2. Huang WC, Elkin EB, Levey AS, et al. Partial nephrectomy versus radical nephrectomy in patients with small renal tumors-is there a difference in mortality and cardiovascular outcomes? J Urol 2009;181:55-61.

3. Thompson RH, Boorjian SA, Lohse CM, et al. Radical nephrectomy for pTla renal masses may be associated with decreased overall survival compared with partial nephrectomy. J Urol 2008;179:468-71.

4. Campbell SC, Novick AC, Belldegrun A et al. Guideline for management of the clinical T1 renal mass. J Urol 2009; 182:1271-9.

5. Pouliot $F$, Pantuck A, Imbeault A, et al. Multivariate analysis of the factors involved in loss of renal differential function after laparoscopic partial nephrectomy: a role for warm ischemia time. Can Urol Assoc J 2011;5: 89-95; DO1:10.5489/cuaj.10044

6. Lane BR, Russo P, Uzzo RG, et al. Comparison of cold and warm ischemia during partial nephrectomy in 660 solitary kidneys reveals predominant role of nonmodifiable factors in determining ultimate renal function. J Urol 201 1;185:421-7.

7. Thompson RH, Lane BR, Lohse CM, et al. Every minute counts when the renal hilum is clamped during partial nephrectomy. Eur Urol 2010;58:340-5.

Correspondence: Dr. Robert Abouassaly, Urological Institute, University Hospitals Case Medical Center 11100 Euclid Ave, Mailstop LKD 5046, Office 4565 Cleveland, OH 44106; fax: 216-844-1900; robert.abouassaly@UHhospitals.org 